\title{
Soluble CD14 Subtype (Presepsin) Assay for Early Diagnosis of Sepsis in Egyptian Patients
}

\author{
MALAKA Z. AMER, M.D.*; SALLY M. SABER, M.D.*; MARWA A. EL-ASHRY, M.D.* and \\ HAYAM A. HEBAH, M.D.** \\ The Departments of Clinical Pathology* and Internal Medicine \& Nephrology**, Faculty of Medicine, Ain Shams University, \\ Cairo, Egypt
}

\begin{abstract}
Background: Despite advances in therapy, sepsis is the leading cause of death in critical care settings. The early recognition of sepsis as well as the speed and appropriateness of therapy in the initial hours after presentation are likely to influence the outcomes of septic patients. This study was conducted to investigate the early diagnostic and differentiating value of pathfast presepsin assay (soluble CD14 subtype) compared to other biomarkers in patients presenting at emergency department with systemic inflammatory response syndrome and suspected sepsis.
\end{abstract}

Methods: The current study included seventy suspected septic patients (patient group) and thirty apparently healthy individuals (control group). All subjects were subjected at first presentation to determination of plasma presepsin, quantitative C-reactive protein and total leucocytic count values, while patient group were subjected to blood culture as a gold standard method.

Results: Presepsin levels showed a statistically significant increase between septic and systemic inflammatory response patients. The cut off value that gave the best sensitivity and specificity for presepsin was $395 \mathrm{pg} / \mathrm{ml}$.

Conclusions: Presepsin can be a very useful promising biomarker not only for the early diagnosis of sepsis (15min) with discrimination between sepsis and systemic inflammatory response syndrome in patient presented in ED, but also for assessment of its severity and prognosis. Higher level was correlated with poor patient outcome. Future studies on large scale are needed to monitoring of prespsin level in response to antibiotic treatment.

Key Words: CRP - Presepsi-Procalcitonin - Sepsis - SIRS.

\section{Introduction}

SEPSIS, severe sepsis and septic shock are some of the most common conditions handled in the Emergency Department (ED). Despite modern

Correspondence to: Dr. Marwa A. El-Ashry, E-mail: marwa.gabr@med.asu.edu.eg antibiotic therapy in conjunction with cardiovascular and respiratory support, mortality rates remain high; between $30 \%$ and $60 \%$. According to the recent (2012) guidelines, by the Surviving Sepsis Campaign, early recognition of these conditions as well as the speed and appropriateness of therapy in the initial hours after presentation are likely to influence the outcomes of septic patients. The rescue principles indicate that sepsis should be diagnosed early by high sensitivity and specificity sepsis biomarkers and treated early by antibiotics given within 1 hour after the diagnosis of sepsis) [1].

Reliance on blood culture as a gold standard method for diagnosis of sepsis has got limitations; as at least two sets of blood cultures (both aerobic and anaerobic bottles) before antimicrobial therapy should be obtained. Sampling error, insufficient volume for blood cultures and reported low sensitivity (30-60\%) are other limitations. Long turnaround time (median time to positivity is around 15 hours) and some false negative cases (slowly growing or fastidious organism) also can lead to a delay in antibiotic administration and devastating consequences regarding patients' mortality $[2,3]$.

Consequently, various adjunctive laboratory diagnostic tests, including biochemical markers; Procalcitonin (PCT), C-reactive protein (CRP) and Interleukin (IL-6), are commonly used in the diagnosis of sepsis while assessing the severity of infection. IL-6 is a sensitive marker in the early phase of infection; however it cannot be used as a reliable marker in the later stages of disease, due to its short half-life [4]. PCT increases in various non-infectious causes of Systemic inflammatory response syndrome (SIRS) i.e., cardiac arrest and severe trauma [5]. CRP is slow kinetic, independent 
of infection severity and increases in many inflammatory diseases [6]. These findings question their ability to distinguish sepsis from SIRS.

Soluble cluster of differentiation 14 subtype (sCD14-ST) so called presepsin, is cleaved from the monocyte/macrophage-specific CD14 receptor complex after binding with lipopolysaccharides (LPS) and LPS binding protein (LPB) during systemic infections [7]. Presepsin appears to reveal significant diagnostic capacity to diagnose sepsis, severe sepsis and septic shock compared to PCT in patients presenting to the emergency department [8].

This study aims to investigate the early diagnostic and differentiating value of presepsin compared to CRP, blood culture and Total Leucocytic count (TLC) in patients presenting at our hospital ED with SIRS and suspected sepsis.

\section{Patients and Methods}

This study was conducted at Ain Shams University Hospitals, Cairo, Egypt, in the period between November 2016 and March 2017. This case control study was conducted on 70 patients (group I) presenting to the ED who met at least two criteria for SIRS and in whom sepsis, sever sepsis or septic shock were suspected to be the primary or concurrent diagnosis according to the guidelines of the American College of Chest Physicians/Society of Critical Care Medicine (AC$\mathrm{CP} / \mathrm{SCCM}$ ) and the International Surviving Sepsis Campaign Guidelines Committee [9]. These guidelines are: Body temperature higher than $38^{\circ} \mathrm{C}$ or lower than $36^{\circ} \mathrm{C}$, hyperventilation evidenced by respiratory rate higher than $20 / \mathrm{min}$ or $\mathrm{PaCO} 2$ lower than $32 \mathrm{mmHg}$, white blood cell count higher than 12,000 cells/ Lowlower than 4,000/ Land heart rate higher than $90 / \mathrm{min}$. Informed consent to participate in the study was obtained from the patients or their families. Another thirty apparently healthy individuals matched for age and gender were recruited as a control group (group II). All study participants (or person's parent or legal guardian) in this research has given written consent to the inclusion of material pertaining to themselves.

In Group I, Patient demographic data, clinical diagnosis and medical records including associated co-morbidities, radiological, laboratory tests (liver,kidney function tests and arterial blood gases) total leucocytic count (TLC),) and microbiological culture results were recorded. Venous blood was collected from group I under complete a septic conditions for blood culture and from both groups for of presepsin and CRP assays. Follow-up of the admitted patients' for survival, for one month from first evaluation in ED was observed.

\section{Patients' exclusion criteria:}

The following subjects were excluded from this study; patients younger than 18 years old, at a terminal stage of diseases, those who received antibiotics in the previous $48 \mathrm{~h}$, or suffering from severe burns. Also, patients with microbiologically proven viral or parasitic infections, and tuberculosis were excluded.

\section{Ethical approval:}

The research has been approved by the ethical committee in Ain Shams university Hospital.

\section{Specimens collection:}

All mandatory laboratory health and safety procedures have been complied. Samples were collected before the start of antibiotic therapy. Ten milliliters $(\mathrm{ml})$ of venous blood were collected for blood culture using BD BACTECTM 9050 Blood Culture System under complete aseptic conditions. Another five $\mathrm{ml}$ of venous blood were collected from both groups. The collected blood was divided into 2 tubes; one for CRP assay, the other on Ethylenediaminetetraacetic acid (EDTA) for presepsin assay.

\section{Blood culture processing and reporting:}

Blood culture bottles were incubated for 5 days in BACTEC instrument. Bottles with positive signal were subcultured on blood (aerobically and anaerobically), chocolate and macConkey agar plates with direct Gram staining of organisms. Identification of growing colonies was done using routine phenotypic methods and Vitek2 compact system (bioMérieux, France).

\section{Quantitative serum CRP assay:}

Gel activated vacutainer was used and assay was determined using Dimension ${ }^{\circledR}$ clinical chemistry system using Flex ${ }^{\circledR}$ reagent cartilage (particle enhanced turbidimetric immunoassay technique). Assay range is $0.5-250 \mathrm{mg} / \mathrm{l})$. CRP results less than $0.5 \mathrm{mg} / \mathrm{L}$ is considered negative and expected value for CRP in healthy individuals is below $3.0 \mathrm{mg} / \mathrm{l}$.

\section{Plasma presepsin assay:}

EDTA (K3EDTA) vacutainer with concentration of $1.2 \mathrm{mg}$ of the anhydrous salt per $\mathrm{ml}$ of blood was collected. The samples were centrifuged at $3000 \mathrm{rpm}$ for 10 minutes and the plasma stored at $-20^{\circ} \mathrm{C}$ until assayed for Presepsin using PATHFAST® immune analysis system (Mitsubishi Chemical Medience Corporation., Tokyo, Japan). The test principle is based on non-competitive 
chemiluminescent enzyme immunoassay (CLEIA). During incubation of the sample with alkaline phosphatase labeled anti presepsin polyclonal antibody and anti presepsin monoclonal antibody coated magnetic particles, the presepsin of the sample binds to the anti presepsin antibodies forming an immunocomplex with enzyme labeled antibody and antibody coated magnetic particles. After removing the unbound substances, a chemiluminescent substrate was added. After a short incubation, the luminescence intensity generated by the enzyme reaction was measured. The luminescence intensity was related to the presepsin concentration of the sample which is calculated by means of a standard curve. The assay time didn't exceed 17 minutes. Quality Control (QC) assay was performed after every calibration to check the calibration curves and to obtain data from QC samples for quality control. The assay was carried according to PATHFAST ${ }^{\circledR}$ manufacturer's instructions. Assay range: $20-20,000 \mathrm{pg} / \mathrm{ml}$. Normal reference range: $60-365 \mathrm{pg} / \mathrm{ml}$.

\section{Statistical analysis:}

The data were analyzed using IBM SPSS advanced statistics (version 23.0, Chicago, IL, USA, 2015) was used for data analysis. Date was expressed as Median and Percentiles for quantitative non-parametric measures and both number and percentage for categorized data. Comparison between two independent groups for non-parametric data was done using Wilcoxon Rank Sum test and Chi-square test to study the association between each 2 variables or comparison between 2 independent groups as regards the categorized data. The probability of error ( $p$-value) $<0.05$ was considered statistically significant, and at $\leqslant 0.01$ and $\leqslant 0.001$ was considered highly significant. $p$-value $>0.05$ was considered statistically non-significant. Diagnostic validity test (diagnostic sensitivity and specificity, positive and negative predictive values and test efficacy) were applied.

\section{Results}

\section{Description of the study participants:}

A total of 100 subjects were included in the study. Seventy of them were enrolled as patient group (suspected sepsis) with ages ranged between 32-60 years (yrs.) old and median 39 yrs. Group I were 38 males $(54.3 \%)$ ) \& 32 females $(45.7 \%)$. Group II were thirty subjects (control group). Their ages ranged between $30-58$ yrs. with median 38 yrs. They were 37 males (53\%) and 33 females $(47 \%)$. Classification of patient group was done according to clinical \& laboratory records into 2 subgroups; SIRS group 20/70 (28.6\%) and septic group 50/70 (71.4\%). Septic group was further subdivided into severe sepsis 30/70 (42.8\%) and septic shock 20/70 (28.6\%).

Definitive diagnosis of SIRS patients included in the study varied among different clinical conditions; acute pancreatitis, acute appendicitis, rheumatic disease (Rheumatoid arthritis and systemic lupus erythematosus), acute cholecystitis and acute peritonitis. The source of sepsis in the septic group was respiratory $28 / 50(56 \%)$, urinary $16 / 50(32 \%)$, central nervous system "meningitis" 4/50 (8\%) and intestinal 2/50 (4\%).

\section{Results of blood culture in patient group:}

The results of blood cultures in group I showed that $40 / 70(57.1 \%)$ were positive results for bacterial growth where SIRS group were blood culture negative and 40/50 (80\%) of septic group were positive. Organisms detected were Klebsiella pneumoniae 14/50 (28\%) Streptococcus pneumoniae 6/50 (12\%), Escherichia (E.coli) 4/50 (8\%), Staph aureus $4 / 50$ (8\%), Pseudomonas aeruginosa 4/50 $(8 \%)$. Acinetobacter baumannii 2/50 (4\%), Neisseria meningitides $2 / 50(4 \%)$, Proteus mirabilis $2 / 50$ (4\%) and Salmonella typhi 2/50 (4\%).

Plasma presepsin assay regards intensive care unit admission:

There was no statistical significant difference between plasma level of presepsin as regards intensive care unit (ICU) admission in septic group $(p>0.05)$.

Plasma presepsin assay and survival rate among group I:

It was found that plasma level concentrations of presep sin in non-survived patients were highly significantly higher than survived patients $(p$ $>0.001)$. However it was non-significant regarding CRP level.

\section{Plasma presepsin assay cut off value:}

Receiver Operating Characteristic (ROC) curve was done for determining the presepsin cut off point of mortality which was $2720 \mathrm{pg} / \mathrm{ml}$ with $(100 \%)$ sensitivity and specificity.

Comparison between different biomarkers among the studied groups:

The Comparison between suspected patients group and control group regarding the presepsin levels was statistically significant $(p<0.05)$. However, in CRP and TLC it was highly significant $(p<0.001)$. The Comparison between septic group and control group regarding presepsin and TLC 
was highly significant $(p<0.001)$. However in CRP it was significant $(p<0.05)$.

As regards the comparison between septic group and SIRS group the presepsin level difference was statistically significant $(p<0.05)$. However, in CRP and TLC it was non-significant $(p>0.05)$ (Table

It was found that presepsin level in SIRS group was higher than in the control group and statistically highly significant. However CRP and TLC; although higher in SIRS group than control group, was statistically non-significant $(p>0.05)$ (Table

The Comparison between septic group and nonseptic group which include SIRS group (20) and control group (70) regarding the presepsin was statistically highly significant $(p<0.001)$. However in CRP and TLC it was statistically non-significant $(p>0.05)$.

Table (1): Comparison between septic group and SIRS group regarding the different laboratory parameters.

\begin{tabular}{|c|c|c|c|}
\hline Variable & $\begin{array}{c}\text { Septic group } \\
n=50\end{array}$ & $\begin{array}{c}\text { SIRS group } \\
n=20\end{array}$ & $p$-value \\
\hline \multicolumn{4}{|c|}{ Presepsin $(\mathrm{pg} / \mathrm{ml})$ : } \\
\hline Median & 1,347 & 352 & \multirow{3}{*}{$0.03(\mathrm{~S})$} \\
\hline Range & 404-18,909 & $300-395$ & \\
\hline IQR & $745-2,782$ & $325-388$ & \\
\hline \multicolumn{4}{|l|}{$C R P(m g / l):$} \\
\hline Median & 4.3 & 13.2 & \multirow{3}{*}{$0.47(\mathrm{NS})$} \\
\hline Range & $1-91.7$ & $1.4-52.1$ & \\
\hline IQR & $3-23$ & $2.5-20$ & \\
\hline \multicolumn{4}{|c|}{$\operatorname{TLC}\left(\times 10^{3} / \mathbf{g}\right) \cdot \mathbf{2}$} \\
\hline Median & 1,100 & 16,935 & \multirow{3}{*}{$0.15(\mathrm{NS})$} \\
\hline Range & $2,600-21420$ & $3,000-24,000$ & \\
\hline IQR & $6,100-16,230$ & $5,170-20,600$ & \\
\hline
\end{tabular}

TLC : Total Leucocytic Count. CRP : C - reactive protein.

IQR : Interquartile Range. NS : Non-Significant.

$\mathrm{S}$ : Significant.
It was found that plasma presepsin assay was highly significantly higher in septic shock group than septic group $(p>0.001)$. However, no statistical significance difference was observed regarding CRP and TLC $(p>0.05)$ (Table 3).

As regards ROC curve analysis of plasma presepsin assay, the best cut off point was $395 \mathrm{pg} / \mathrm{ml}$ to discriminate between septic \& SIRS patients. The AUC of presepsin to discriminate between different groups (1.000) was higher than that of CRP. The best cut off point for CRP was $7.6(\mathrm{mg} / \mathrm{l})$ to discriminate between SIRS and septic group which was invalid statistically (Table 4).

The best cut off point of presepsin to discriminate between patient group and control group was $320 \mathrm{pg} / \mathrm{ml}$ with sensitivity $100 \%$, specificity $68 \%$ and efficacy $84 \%$. However, to discriminate between septic patients and SIRS patients the best cut off point was $395 \mathrm{pg} / \mathrm{ml}$ with sensitivity $100 \%$, specificity $100 \%$ and efficacy $100 \%$.

Table (2): Comparison between control group and SIRS group regarding the different laboratory parameters.

\begin{tabular}{|c|c|c|c|}
\hline Variable & $\begin{array}{l}\text { SIRS group } \\
n=50\end{array}$ & $\begin{array}{l}\text { Control group } \\
\qquad n=20\end{array}$ & $p$-value \\
\hline \multicolumn{4}{|c|}{ Presepsin $(\mathrm{pg} / \mathrm{ml})$ : } \\
\hline Median & 352 & 209 & \multirow{3}{*}{$0.000(\mathrm{HS})$} \\
\hline Range & $300-395$ & $97-320$ & \\
\hline IQR & $325-388$ & $121-298$ & \\
\hline \multicolumn{4}{|l|}{$\operatorname{CRP}(\mathrm{mg} / \mathrm{l}):$} \\
\hline Median & 13.2 & 4.5 & \multirow{3}{*}{$0.28(\mathrm{NS})$} \\
\hline Range & $1.4-52.1$ & $1.5-8.8$ & \\
\hline IQR & $2.5-20$ & $3.2-5.6$ & \\
\hline \multicolumn{4}{|c|}{$\operatorname{TLC}\left(x 10^{3} / \mathbf{I}\right) \cdot \mathbf{L}$} \\
\hline Median & 16,935 & 6,900 & \multirow{3}{*}{$0.12(\mathrm{NS})$} \\
\hline Range & $3,000-24,000$ & $4,800-9,700$ & \\
\hline IQR & $5,170-20,600$ & $5,200-8,100$ & \\
\hline
\end{tabular}

Table (3): Comparison between patients with sepsis and patients with septic shock regarding different laboratory parameters.

\begin{tabular}{|c|c|c|c|c|c|c|}
\hline Variable & $\mathrm{N}$ & Median & $25 \%$ & $75 \%$ & Range & $p$-value \\
\hline \multicolumn{7}{|l|}{$\operatorname{TLC}\left(x 10^{3} / \mathbf{y}\right) \cdot \mathbf{L}$} \\
\hline Septic Shock & 20 & 13,175 & $9,607.5$ & 17,170 & $4,500-19,100$ & 0.258 \\
\hline Sepsis & 30 & 8400 & 4,435 & $15,757.5$ & $2,600-21,420$ & (NS) \\
\hline \multicolumn{7}{|l|}{$C R P$} \\
\hline Septic Shock & 20 & 3 & 2.9 & 10.6 & $2-91.7$ & 0.576 \\
\hline Sepsis & 30 & 11 & 2.75 & 26.475 & $1-58.5$ & (NS) \\
\hline \multicolumn{7}{|l|}{ Presepsin: } \\
\hline Septic Shock & 20 & 3751 & 2596.5 & 5917 & 2190-18909 & 0.000 \\
\hline Sepsis & 30 & 579 & 571.75 & 1018.5 & $420-550$ & (HS) \\
\hline
\end{tabular}

TLC: Total Leucocytic Count. CRP: C - reactive protein. NS : Non-Significant. HS: Highly Significant. 
Table (4): AUC and the best cut off point for presepsin plasma level and CRP.

\begin{tabular}{lcccc}
\hline Variable & AUC & Cutoff value & Sensitivity $\%$ & Specificity $\%$ \\
\hline Presepsin $(p g / m l):$ & & & & \\
$\quad$ Septic with control & 1.000 & 320 & 100 & 100 \\
Septic with SIRS & 1.000 & 395 & 100 & 80 \\
SIRS with control & 0.968 & 320 & 100 & 60 \\
CRP $(m g / l)$ : & & & & 50 \\
Septic with control & 0.544 & 4.7 & $* 48(<50 \%)$ & 60 \\
Septic with SIRS & 0.505 & 7.6 & $* 44(<50 \%)$ & \\
SIRS with control & 0.672 & 6.5 & 93.3 & \\
\hline \multicolumn{2}{l}{ SIRS: Systemic Inflammatory Response Syndrome. AUC: Area under ROC curves. *: In valid statistically. }
\end{tabular}

\section{Discussion}

Sepsis is a systemic response to infection and can lead to sever sepsis or septic shock. Sever sepsis and septic shock are frequently handled in the ED and despite modern antibiotic therapy the mortality rate remain high [9]. Severe sepsis and septic shock were considered a unique group because of the similar clinical and prognostic features of these conditions. Early diagnosis of sepsis is difficult and the clinical presentation can be misleading especially in patients with several comorbidities [1] . CRP is one of the acute phase inflammation proteins synthesized by the liver, its main advantage is its great sensitivity, but unfortunately it is weakly specific for bacterial infections. Moreover, the evolution of sepsis is poorly correlated with changes in serum CRP level [10]

Recent biomarkers and inflammatory variables could contribute to early prompt identification \& differentiation of septic patients from those with SIRS [1]. Among different recent biomarkers that appear to be promising in diagnosis of early stages of septic process were procalcitonin, presepsin, IL-6 and CD64 [11].

Procalcitonin level increases 4 hours after infection, reaches a plateau slowly at 8-24 hours, and reaches the peak one day after infection. While, presepsin being increased earlier and faster in patients with sepsis ( 2 hours after infection, peaked at 3 hours of infection). Pathfast ${ }^{\circledR}$ presepsin assay is now available and could be used on a point-ofcare testing basis, thus allowing the emergency physician to get presepsin values in a short time from whole blood samples [12].

In this research a prospective study was designed to validate the diagnostic and differentiating role of presepsin for septic and SIRS patients in ED alone and compared with a quantitative level of CRP, and also TLC which is routinely done for septic patients.
It was found that more than $70 \%$ of ED suspected sepsis cases were actually septic. This may be due to the low socio economic level with low immunity and low awareness about the progress of the diseases and the routes of transmission which agreed with Ulla et al., who reported that severe sepsis and septic shock are frequently handled in ED [9].

According to the analysis of the clinical records, definitive diagnosis of patients affected by SIRS was due to acute pathologies such as mainly acute pancreatitis, burns, acute appendicitis, acute cholecystitis and also diseases of autoimmune origin but with no evidence of infection and negative blood culture. These results were in agreement with Ulla et al., who mentioned that acute pancreatitis represented $22 \%$ of SIRS cases [9].

Klebsiella pneumoniae was the most common organism (28\%) responsible for sepsis in this study. This comes in agreement with the study of Dzwonek et al., in which nearly half of the positive blood cultures grew Klebsiella pneumonia [9], also in the study of de Benedetti et al., the most common isolated pathogen was Klebsiella pneumoniae (47.5\%) [14]. The presence of hospital strains like Acinetobacter baumannii and Pseudomonas aeruginosa could be attributed to previous hospital admission of these cases.

In the present study the presepsin level concentration was higher statistically in non survivors (5 days mortality rate) compared with survivors. We found that the presepsin cut off point $2720 \mathrm{pg} / \mathrm{ml}$ to discriminate non survived patients from survived and this was in agreement with Ulla et al. [9]. They demonstrated that 60 days hospital mortality was higher in patients with initial values of presepsin greater than $1000 \mathrm{pg} / \mathrm{ml}$ than in groups with lower values with no role of procalcitonin in the first evaluation in ED. These results pointed out the possible prognostic role of presepsin in predicting 
the hospital mortality and promptly identify the high risk patients.

A non-significant positive correlations was detected between the different laboratory parameters (presepsin, CRP and TLC), the highest correlation was in presepsin and TLC $(r=0.231)$. The insignificance obtained in these results may be attributed to the relative small sample size of the studied group.

As regards the comparison between plasma presepsin assay between the patient group (septic and SIRS) and the control group, a statistically significant increase of presepsin in patient group was observed. Also several studies found that presepsin significantly increases in blood stream at the early stage of sepsis and inflammation $[7,15]$ CRP and TLC recorded a highly statistical significant difference between patient group and control group as they are highly sensitive acute phase reactants. The levels of presepsin and TLC in septic group (sepsis and septic shock) were significantly higher than those in control group. Our results were in agreement with that of Vodnik et al., [16]

Levels of presepsin in our study were the highest among septic patients followed by SIRS patients then the lowest value was observed in control group. A significant statistical difference was shown when septic patients were compared to controls and when septic group were compared to SIRS. It was highly significant when SIRS group compared with control group. Shozushima et al., noted on their study that presepsin was the best marker compared to other markers when the patients were classified into normal, local infection, SIRS, sepsis, and severe sepsis [7].

Liu et al., [15] noticed that AUC of presepsin was higher than that of PCT and displayed higher sensitivity in predicting septic shock which further indicated that presepsin was superior to PCT in the assessment of prognosis as reported by Charles et al., They noticed that the magnitude of PCT elevation on day one does not reliably predict the outcome in patients with sepsis [17].

Castelli et al., found that PCT concentrations were higher in patients in whom infection was diagnosed at comparable levels of organ dysfunction and was higher in patients with sepsis than in SIRS patients [10]. On the other hand Hryckiewicz et al. mentioned that measurement of PCT level on the first, second and third days of hospitalization has no prognostic value [18]
Concerning CRP (being weakly specific for bacterial infections and the evolution of sepsis is poorly correlated with changes in serum CRP level [19]), in our study its' values were not statistically significant when we compared between septic patients \& SIRS patients and the control group \& SIRS patients.

Presepsin as a biomarker is not only suitable for the early diagnosis of sepsis, but also for the assessment of its severity and prognosis. The presepsin level was significantly higher in septic shock than in sepsis patients. The present study demonstrated that plasma presepsin assay was a good parameter for reflecting the severity of sepsis like other similar studies $[13,16]$. On the contrary, Ulla et al., observed that no difference in presepsin levels was found between the sepsis and septic shock groups. They suggest that the concentration of the biomarker is not related to the severity of the disease in the very early hours [19].

ROC curve was used to assess the value of the presepsin and CRP in the diagnosis of sepsis; the results showed that AUC of presepsin was bigger than that of CRP when we compared between all groups (control, SIRS, control) included in the study. This finding was in concordance with other studies $[8,15,16]$

In our study Presepsin level at point 320pg/ml the specificity was $68 \%$ but the sensitivity was $100 \%$ while cut-off point of $395 \mathrm{pg} / \mathrm{ml}$ has the same sensitivity $(100 \%)$ but with better specificity $(100 \%)$. Whereas Ulla et al., suggested a cut-off value $600 \mathrm{pg} / \mathrm{ml}$ of presepsin for diagnosis of sepsis which gives sensitivity $78.95 \%$ and specificity $61.9 \%$ [9]. However, Liu et al., chose a point 550pg/ $\mathrm{ml}$ improving sensitivity to $85 \%$ and reported specificity was $63.6 \%$ [15].

Concerning the difference between previous studies and ours as regards presepsin plasma assay may be due to different sample size (affects the internal and external validity of the study) or different degree of the severity of the sepsis in the population studied. So, our suggestion is to use this cut-off point $(395 \mathrm{pg} / \mathrm{ml})$ for sepsis diagnosis. The different cut-off points in our study could be explained as a correlation to different rate of infections and small sample size.

\section{Conclusion:}

Presepsin can be a very useful promising biomarker not only for the early diagnosis of sepsis (15min) with discrimination between sepsis and systemic inflammatory response syndrome in pa- 
tient presented in ED, but also for assessment of its severity and prognosis. Higher level was correlated with poor patient outcome.

Funding: None.

Conflicts of interest: None.

\section{References}

1- DELLINGER R., LEVY M., RHODES A., ANNANE D., GERLACH H., OPAL S., et al.: Surviving sepsis campaign: international guidelines for management of severe sepsis and septic shock. Crit. Care. Med., 41 (2): 580637, 2013.

2- LEVER A. and MACKENZIE I.: Sepsis: Definition, epidemiology, and diagnosis. BMJ, 335: 879-83, 2007.

3- MORGENTHALER N. and KOSTRZEWA M.: Rapid Identification of Pathogens in Positive Blood Culture of Patients with Sepsis: Review and Meta-Analysis of the Performance of the Sepsityper Kit. Int. J. Microbiol., doi.org/10.1155/2015/827416, 2015.

4- BHARTIYA D., KAPADIA C., SANGHVI K., SINGH H., KELKAR R. and MERCHANT R.: Preliminary studies on IL-6 levels in healthy and septic Indian neonates. Indian Pediatr., 37 (12): 1361-67, 2000.

5- WACKER C., PRKNO A., BRUNKHORST F. and SCHLATTMANN P.: Procalcitonin as a diagnostic marker for sepsis: a systematic review and meta-analysis. Lancet Infect. Dis., 13 (5): 426-35, 2013.

6- SIMON L., GAUVIN F., AMRE D., SAINT-LOUIS P. and LACROIX J.: Serum procalcitonin and C-reactive protein levels as markers of bacterial infection: A systematic review and meta-analysis. Clin. Infect. Dis., 39 (2): 206-7, 2004.

7- SHOZUSHIMA T., TAKAHASHI G., MATSUMOTO N., KOJIKA M., OKAMURA Y. and ENDO S.: Usefulness of presepsin (sCD14-ST) measurements as a marker for the diagnosis and severity of sepsis that satisfied diagnostic criteria of systemic inflammatory response syndrome. J. Infect. Chemother., 17 (6): 764- 9, 2011.

8- ENDO S., SUZUKI Y., TAKAHASHI G., SHOZUSHIMA T., ISHIKURA H. and MURAI A.: Usefulness of presepsin in the diagnosis of sepsis in a multicenter prospective study. J. Infect. Chemother., 18 (6): 891-7, 2012.

9- ULLA M., PIZZOLATO E., LUCCHIARI M., LOIACONO M., SOARDO F., FORNO D., et al.: Diagnostic and prognostic value of presepsin in the management of sepsis in the emergency department: A multicenter prospective study. Crit. Care., 17 (4): R168. doi: 10.1186/ cc12847, 2013.

10- CASTELLi G., POGNANI C., MEISNER M., STUANI A., BELLOMI D. and SGARBI L.: Procalcitonin and Creactive protein during systemic inflammatory response syndrome, sepsis and organ dysfunction. Crit. Care., 8 (4): 234- 42, 2004.

11-PALMIERE C., MUSSAP M., BARDY D., CIBECCHINI F. and MANGIN P.: Diagnostic value of soluble CD14 subtype (sCD14-ST) presepsin for the postmortem diagnosis of sepsis-related fatalities. Int. J. Legal Med., 127 (4): 799-808, 2013.

12- OKAMURAA Y. and YOKOI H.: Development of a pointof-care assay system for measurement of presepsin (sCD14-ST). Clin. Chim. Acta., 412 (23-24): 2157- 61, 2011.

13- DZWONEK A., NETH O., THIEBAUT R., GULCZYNSKA E., CHILTON M., HELLWIG T., et al.: The role of mannose-binding lectin in susceptibility to infection in preterm neonates. Pediatr. Res., 63 (6): 680-5, 2008.

14- DE BENEDETTI F., AURITI C., D'URBANO L., RONCHETTI M., RAVA L., TOZZI A., et al.: Low serum levels of mannose binding lectin are a risk factor for neonatal sepsis. Pediatr. Res., 61 (3): 325-8, 2007.

15-LIU B., CHEN Y., YIN Q., ZHAO Y. and LI C.: Diagnostic value and prognostic evaluation of Presepsin for sepsis in an emergency department. Crit. Care., 17(5): doi: 10.1186/cc13070, 2013

16- VODNIK T., KALJEVIC G., TADIC T. and MAJKICSINGH N.: Presepsin (sCD14-ST) in preoperative diagnosis of abdominal sepsis. Clin. Chem. Lab. Med., 51 (10): 2053-62, 2013

17- CHARLES P., TINEL C., BARBAR S., AHO S., PRIN S., DOISE J., et al.: Procalcitonin kinetics within the first days of sepsis: Relationship with the appropriateness of antibiotic therapy and the outcome. Crit. Care., 13 (2): R38. doi: 10.1186/cc775, 2009.

18- HRYCKIEWICZ K., JUSZCZYK J., SAMET A., ARLIKOWICZ E, SLEDZINSKA A. and BOLEWSKA B. Procalcitonin as a diagnostic marker in systemic inflammatory response syndrome (SIRS) and sepsis. Przegl. Epidemiol., 60 (1): 7-15, 2006.

19- MUSSAP M., NOTO A., CIBECCHINI F. and FANOS V.: The importance of biomarkers in neonatology. Semin. Fetal. Neonatal. Med., 18 (1): 56-64, 2013. 


\section{فحص النوع الفرعى CD14 (بريسيبسين) للتشخيص المبكر لتلوث مجرى المئين اللدم فى الهرضى الهصرينين}

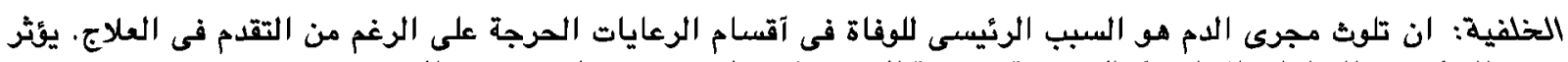

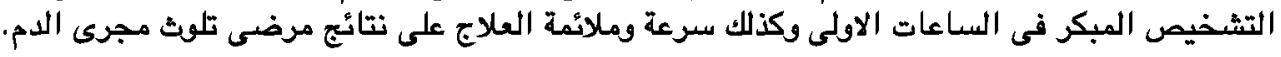

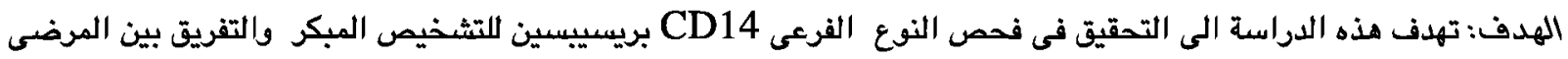

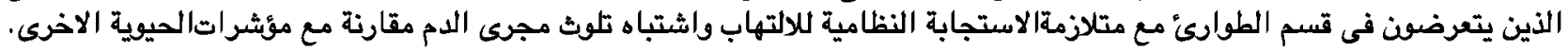

المرضى وطرق البحث: تضمنت هذه الدراسة سبعين مريضا مشتبه اصابته بتلوث الدم (مجموعة المرضى) وثيلا ثين شخصا

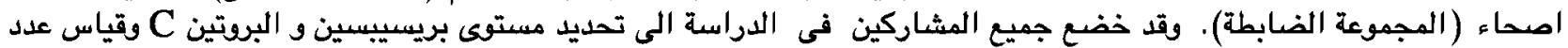

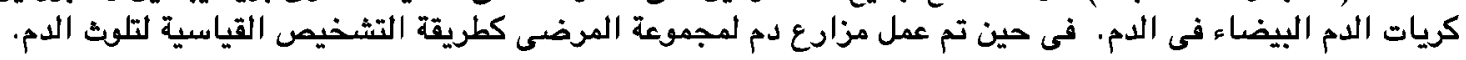

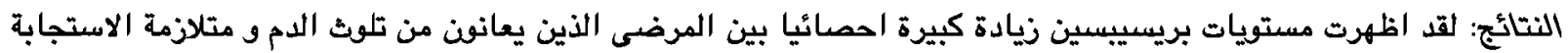

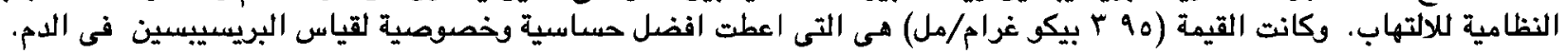

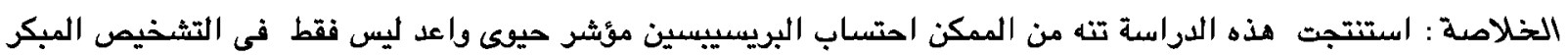

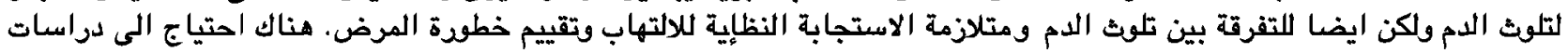

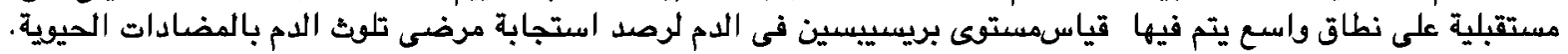

